\section{ASSOCIATED EFFECT OF PERFORATION POSITION AND DIAMETER ON THERMAL PERFORMANCE OF PLANE FIN UNDER NATURAL CONVECTION ENVIRONMENT}

\author{
Osamah Raad Skheel Al-khafaji, Nizar F.O. Al-Muhsen* \\ Middle Technical University, Baghdad, Iraq
}

Article history

Received

20 August 2019

Received in revised form

10 April 2020

Accepted

21 July 2020

Published online

27 August 2020

*Corresponding author nizar.almuhsen@mtu.edu.iq

\begin{abstract}
Graphical abstract

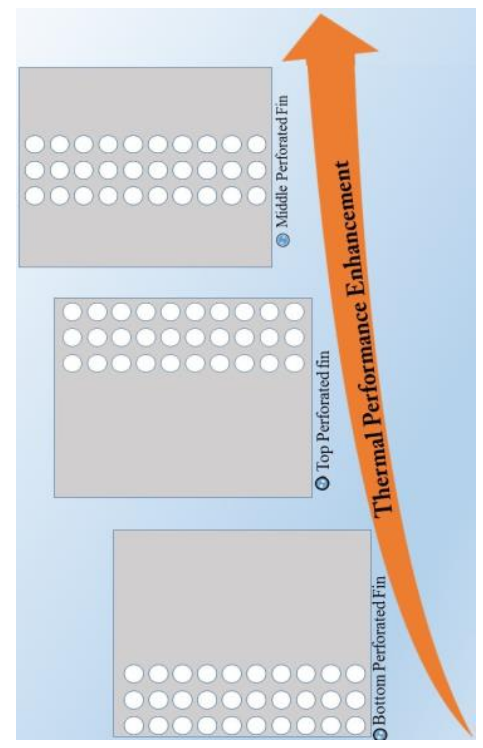

Abstract

The fin perforation represents an efficient way to reduce fins weight and enhance its thermal performance. In this study, rectangular plane fins were designed and fabricated aiming to experimentally investigate the effect of the perforation, perforations position and diameter on the solid fins thermal performance under natural convection heat transfer conditions. The experiments were conducted at a wide range of the supplied heat fluxes, and also covered three perforations positions (bottom, middle, top) and perforations diameters $(3,5,7) \mathrm{mm}$. At all the used diameters, results showed that the middle position for perforations performed the best in terms of the Nusselt number and mean surface temperature. The maximum Nusselt number and mean surface temperature were 662.08 and $71.95 \circ \mathrm{C}$ respectively when the heat flux was $4181.82 \mathrm{~W} / \mathrm{m}^{2}$, and the perforation diameter was $3.0 \mathrm{~mm}$. The thermal performance of the top-perforated fins was slightly smaller than that of the middle-perforated fins. Besides, the bottom perforated fins demonstrated the worst thermal performance in terms of Nusselt number and the mean surface temperature. Regarding the effect of the perforation diameter, the $3.0 \mathrm{~mm}$ showed superior thermal performance compared with $5.0 \mathrm{~mm}$, and $7.0 \mathrm{~mm}$ regardless of the perforation's positions.

Keywords: Perforation positions, perforated plain fins, perforation diameter, Nusselt number, fin temperature distribution

(c) 2020 Penerbit UTM Press. All rights reserved
\end{abstract}

\subsection{INTRODUCTION}

The rapid development and miniaturization revolution of the electronic devices and micro technologies have led to a bigger demand for powerful electronic processors that should be able to process a large amount of data within a short time. However, this can produce greater amount of heat increasing the electronic components temperature drastically [1]. Therefore, more efficient heat removal systems have been urgently required to dissipate the generated heat effectively to maintain the operating temperature of lower than its maximum limits $[2,3]$. Consequently, the processing speed of the electronic devices can be increased, and their weight and size can be also decreased. The conventional air-cooled heat removal systems have been largely adopted as a thermal management solution due to low manufacturing cost and its reliability. However, these heat removal systems are unable to cope with the highly-compact electronic applications from the aspects of weight and size [4]. Fundamentally, the generated heat by any electronic processor can be transferred by conduction to the heat sink, and then to be dissipated to the ambient air by natural, forced or mixed convection methods. Increasing the temperature of electronic devices can reduce their life span or even cause a severe damage to the electronic components. Therefore, an optimized thermal design of heat removal systems such as highly 
efficient heat sink systems and/or perforated heat fins has been widely investigated by many researchers [5, 6].

The review paper carried out by Ahmed et al. [5] highlighted numerous techniques that were adopted aiming to optimize the thermal performance of the heat sinks by using different shapes of heat fins. These techniques were including porous media, different fins' shapes and orientations, micro channel utilization, nano-fluid technology and the use of circular and rectangular perforations for pin fins heat sink. The wide range of thermophysical properties of the nanofluids technologies and their effects on the thermal performance of different geometries of the widely used microchannel heat sinks were reviewed and summarized by Kumar et al. [6]. Furthermore, a comparative study was performed aiming to select the best microchannel heat sink thermal performance in terms of the maximum heat transfer and minimum friction losses. However, all the mentioned research papers in the review papers $[5,6]$ did not investigate the combined effects of the circular perforation, perforation position and perforation sizing on the thermal performance of the flat plate heat fins.

Recently, intensive investigations (experimental and numerical) have been conducted aiming to find an optimal design of the heat removal system that can be able to achieve a greater heat dissipation with a minimum possible size and weight [7]. This could comprise the used material, perforated and interrupted fins. A wide range of fins geometries and different perforations shapes were tested to investigate their effects on the temperature distribution contour across the fin and the heat dissipation efficiency $[5,8,9]$. The effects of perforation shape and size on the heat transfer characteristics of compact cross flow type heat exchangers were experimentally and numerically investigated by lbrahim et al. [10]. Their results showed that the greatest temperature difference of the fins was noticed by $51.29 \%$ when the circular perforation shape was used compared with that at fins tip of the heat collector. This result was followed by percentages of $45.57 \%, 42.28 \%$ and $35.82 \%$ for the rectangular, triangular and without perforation shapes respectively. A numerical investigation (using CFD-ACE+ commercial package) on the geometry of the pin fin array aiming to estimate the optimal design comprising the shape, dimension and perforation diameters of the pin fin [11]. The numerical design showed that the height of the optimal pin fin was reduced, and the perforation diameter (Dperf) was increased compared to that of original design. Moreover, the authors results demonstrated that the Nusselt number (Nu) of the optimal design was increased by around $2.0 \%$, and the average temperature was slightly decreased compared with that of the original design. The effect of multiple circular perforations on the thermal performance of the pin fin heat sink was experimentally and numerically investigated by Al-Damook et al. [12]. Their results showed that, when the number of perforations in the pin fins were increased, the Nu was increased by $11 \%$, and the pressure drop across the heat sink decreased by $16 \%$, compared with that of solid fins. Furthermore, the overall temperature distribution was enhanced with the fins heat sink perforations improving the heat transfer from surface to the surrounding.

Awasarmol and Pise examined the influence of the Derf and fins inclination angle on the heat transfer coefficient under a natural convection heat transfer condition [13]. A significant increment by about $30 \%$ in the heat transfer coefficient was achieved at the inclination angle of 45 degree and $12 \mathrm{~mm}$ Derf compared with that of solid fins. In addition, the combined effect of the number and diameter of the perforations on the surface temperature distribution, heat transfer rate and heat transfer coefficient were experimentally investigated by Al-Doori [14]. The results showed that the thermal performance of the solid fin improved when the number of perforations was increased. Moreover, the temperature differences were obviously decreased with increased perforations number. However, the associated effect of the perforations position and their diameter on the thermal performance of the solid fin have not been investigated yet. In this study, the associated effect of the perforations position and diameters on the solid-fin thermal performance was experimentally investigated. The experiments were conducted at conditions of the natural convection heat transfer. A wide range of the supplied power was used as a heat source to heat up the fins. The results of the Nu number, surface temperature distribution, and mean surface temperature were presented and fundamentally analyzed.

In order to optimize the thermal performance of an aluminum flat-plate fin, the effect of the multiperforations on the convection heat transfer from the flat-plate fins to the surrounding is investigated. Using the circular perforations can enhance heat dissipation from the flat-plate fins regardless of the effect of the perforations' position. This study aims to experimentally investigate the effect of the circular perforation positions on the thermal performance of the flat-plate fins at various perforation diameters. A matrix of 30 perforations $(3 \times 10)$ is positioned at the bottom, middle and top of the flat plate-fin. Meanwhile, constant heat flux is supplied to all the tested fins. The attained results are presented, and comprehensively discussed and analyzed.

\subsection{METHODOLOGY}

\subsection{Experimental Apparatus}

Figure 1 shows the schematic diagram of the perforated fins test rig including the measurement and control systems. Sets of experiments were carried out to investigate the effect of the location of circular perforations on the thermal performance of aluminum 
flat plate fins. The outside dimensions of each fin are $1.0 \mathrm{~mm}$ thickness, $110 \mathrm{~mm}$ for length, and $100 \mathrm{~mm}$ for width. In each fin, 30 circular perforations with diameters of $3.0 \mathrm{~mm}, 5.0 \mathrm{~mm}$ and $7.0 \mathrm{~mm}$ were distributed inside a matrix made of 3 columns and 10 rows, as shown in Figure 2. This matrix was positioned at three different locations which were at the bottom, middle and top of the flat plate fins. Besides, the distances between the perforation's boundaries were fixed at $5.0 \mathrm{~mm}$ longitudinally and transversely. The recorded results from the modified fins were analyzed and compared with the baseline results of the solid (non-perforated) fin.

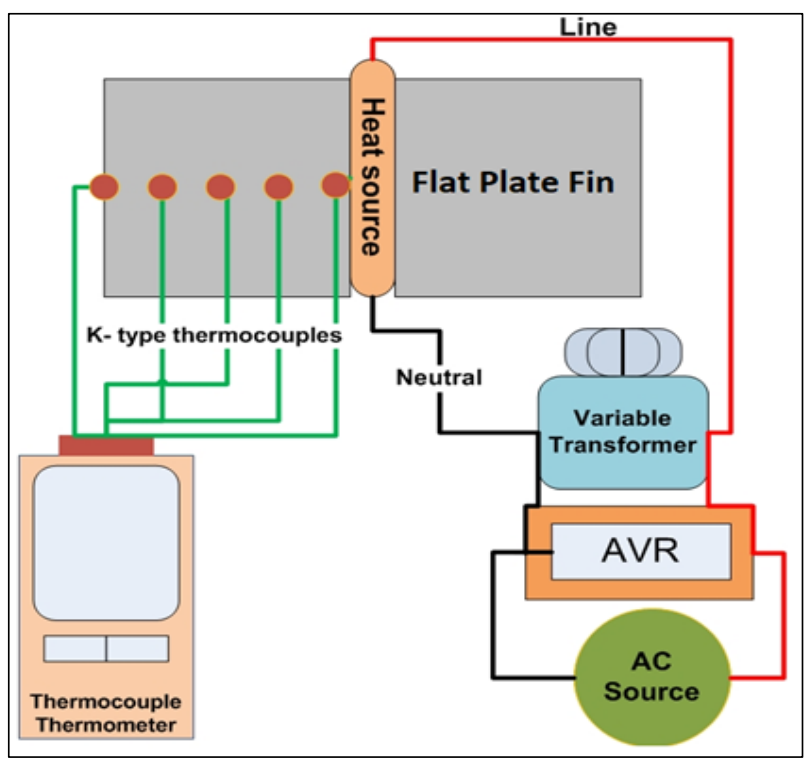

Figure 1 Schematic diagram of the test rig
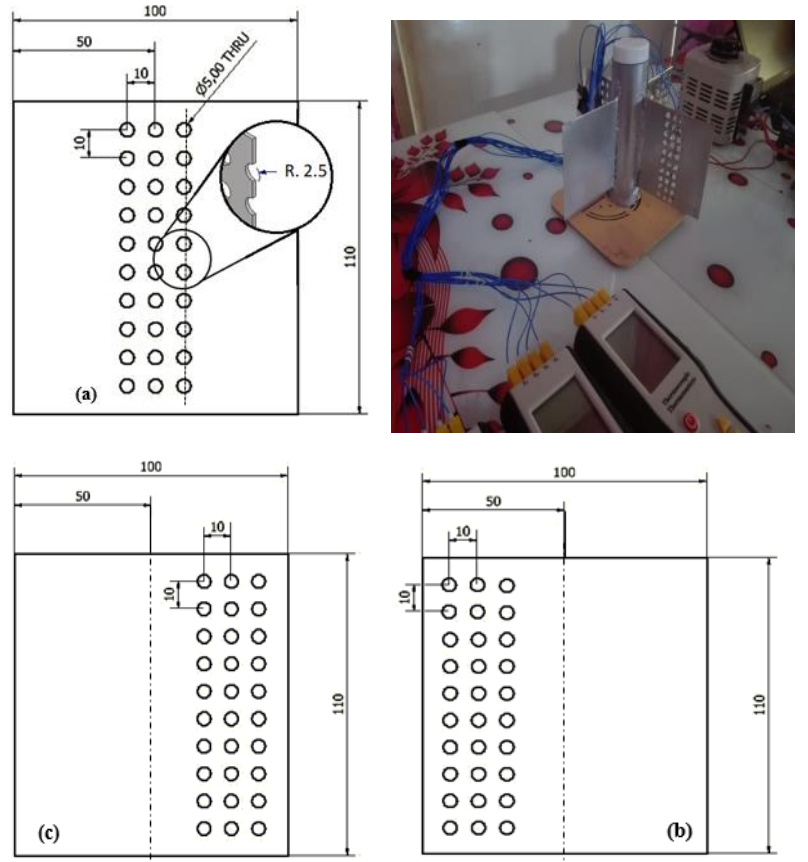

Figure 2 Proposed perforated fin configuration and dimensions (a) Middle- (b) Bottom- (c) Top -perforated design)
The heat source was generated by using a $400 \Omega$ electric heat element, and $0.5 \mathrm{~kW}$ single-phase voltage regulator (AC-Variac) that was used to control the supplied power accurately based on the needs of each testing condition. The main specifications of the AC-Variac are listed in Table 1. To avoid any possible fluctuation in the supplied power to the used heat element, an automatic voltage regulator (AVR-500 W) type JONCHN was used during all the designed experiments, and the output voltage was set at 220 volts. The major specifications of the AVR-500 W device were listed in Table 2. In addition, the flat plate fins were connected vertically to the heat source, and the thermal contact was assured by using a thermo-paste between the fin base and the heat source surfaces. Ninety degree was used as an angular separation distance between the flat plate fins aiming to achieve an even heat distribution from the source to the fins. Three perforations diameters (3.0 $\mathrm{mm}, 5.0 \mathrm{~mm}, 7.0 \mathrm{~mm}$ ) were selected and tested in association with the perforation's positions (bottom, middle, top) on the fin. At each test, twenty K-type thermocouples were used to measure the fin surface temperature of the flat plate fins at the evenly distributed locations. The K-type thermocouple temperature resolution is $0.1^{\circ} \mathrm{C}$. In addition, digital thermocouple thermometers type HT-9815 were used to display and measure the real time temperature from the 12 K-type thermocouples during the conducted experiments. The thermocouple thermometers accuracy is $\pm 1 \circ \mathrm{C}$.

Table 1 Variable transformer specifications (AC-Variac)

\begin{tabular}{c|lc|}
\hline No. & Parameters & Range / Unit \\
\hline 1 & Output power & $0 \sim 500 \mathrm{~W}$ \\
2 & Output voltage (AC) & $10 \sim 250 \mathrm{Volts}$ \\
3 & Output frequency & $50 \sim 60 \mathrm{~Hz}$ \\
4 & Input voltage (AC) & $200-230 \mathrm{Volts}$ \\
5 & Operating temperature & $-15 \sim 50 \circ \mathrm{C}$ \\
6 & Transformation efficiency & $\sim 98 \%$ \\
\hline
\end{tabular}

Table 2 The major specifications of the Automatic voltage regulator (AVR-500 W)

\begin{tabular}{c|l|c|}
\hline No. & Parameters & Range / Unit \\
\hline 1 & Output power & $500 \mathrm{~W}$ \\
2 & Input voltage (AC) & $130 \sim 250 \mathrm{Volts}$ \\
3 & Output frequency & $50 \mathrm{~Hz} / 60 \mathrm{~Hz}$ \\
4 & Regulating time & $>20 \mathrm{Volts} / \mathrm{sec}$ \\
5 & Stabilization precision & $\pm 3 \%$ \\
6 & System efficiency & $>98 \%$ \\
7 & Environment temperature & $-50 \mathrm{C} \sim 40^{\circ} \mathrm{C}$ \\
\hline
\end{tabular}

\subsection{Analysis Procedure}

The experimental methodology and results analysis were governed by using the natural convection heat transfer equations. The supplied heat flux (q") on the tested fins was calculated based on Equation (1) where the input heat to the tested fins was assumed to be equal to the supplied electrical power to the 
used heat element over the perpendicular crosssectional area to the direction of the heat source.

$$
q^{\prime \prime}=\frac{\text { Electrical Input Heat }}{\text { Fin Cross Sectional Area }}=\frac{I * V}{A_{\text {cross. }}}=\frac{q_{E, I n}}{A_{\text {cross. }}}
$$

Where $\mathrm{I}$ and $\mathrm{V}$ are the electrical current and voltage, respectively, provided by the $A C$ variable transformer. The heat losses from the heat source surface to the surrounding was disregarded due to its small value compared with the total input heat. As a result, the electrical input heat was considered as the main heat source to the tested fins. Furthermore, the experimental Nu number and heat transfer coefficient (h) for each fin were calculated based on the realtime experimental results using Equations (2) and (3) respectively.

$$
\begin{aligned}
& N u_{\text {Exp. }}=\frac{h L}{k} \\
& h=\frac{\left[q_{E, I n}\right] / 4}{A_{\text {surf. }} *\left(T_{\text {Mean }}-T_{\infty}\right)} \\
& A_{\text {surf. }}=A_{\text {surf.|solid fin }}-A_{\text {perf. }}
\end{aligned}
$$

Where Asurf. represents the surface area of each tested fin, and it varies with perforation diameter, as shown in Equation 4. Asurf. is equal to the surface area of the solid fin (Asurf./solid fin) minus the perforation cut surface area (Aperf.). TMean is the mean surface temperature of the tested fin, and $T_{\infty}$ is the temperature of the ambient air. The empirical Nu number was calculated based on an empirical correlation at which the Raleigh number (Ra) was within the range of the chosen correlation [14].

To specify the thermal properties of the ambient air, the film temperature $\left(T_{f}\right)$ was used and calculated based on Equation 5 [3]. The film temperature was defined as the mean temperature between the $T_{\text {Mean }}$ of the fin surface and the ambient temperature $\left(T_{\infty}\right)$ [15].

$$
T_{\text {film }}=\frac{\left\{T_{(\text {Mean })}+T_{\infty}\right\}}{2}
$$

\subsection{RESULTS AND DISCUSSION}

\subsection{Nusselt Number}

\subsubsection{Effect of Perforations on Solid Fin Thermal Performance}

Figures $3(a-c)$ show the variations of the experimental Nu number vs the supplied heat flux at different perforation diameters and positions. Regardless of the effect of perforations diameters and positions, it can be noticed that all the Nu numbers increase when the supplied heat flux is increased at all the tested conditions. Besides, the solid fin after the bottomperforated fins demonstrate the worst thermal performance in terms of the Nu numbers and mean surface temperatures compared with the middle and top-perforated fins. These results are highly correlated with a number of published research papers results about the effect of perforations on the thermal performance of the solid fin $[3,11,13]$. When the AC power is supplied to the heat element, the heat starts fluxing through the entire fin by conduction heat transfer [16]. Consequently, the air density near the fins wall may decrease due to the temperature rise in the vicinity of the fins. Because of the bouncy effect, the air that is near the fin surface may begin to flow toward upward enhancing the natural convection heat transfer between the fin surface and the surrounding [15]. While the moving air can flow smoothly near the solid fin wall, the perforations can swirl the air, and create turbulent flow near the fin wall. This might enhance the heat transfer rate from the fin surface to the ambient space [17]. Besides, the turbulent flow may help to break down the thermal sublayers near the fin surface decreasing the thermal resistance and then increasing heat dissipation from the fin to the surrounding. This can be noticed in Figures $3(a-c)$ when the Nu numbers are much smaller at the solid fin and bottom-perforated fins compared with the middle and top-perforated fins.
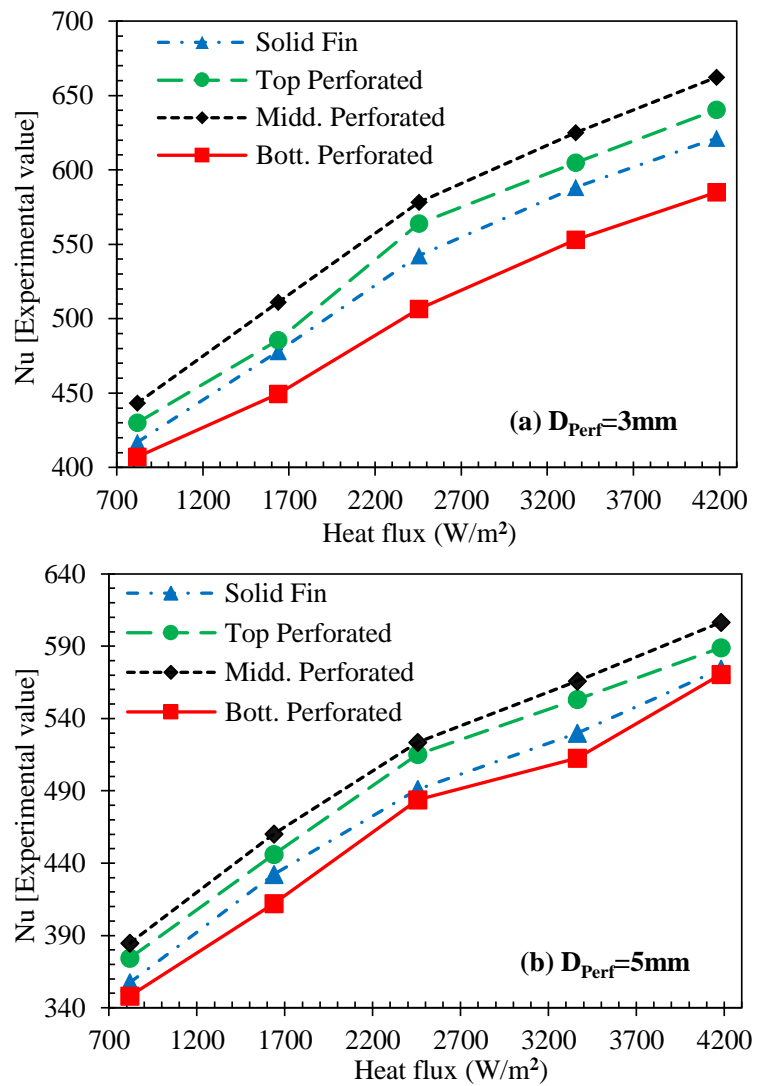


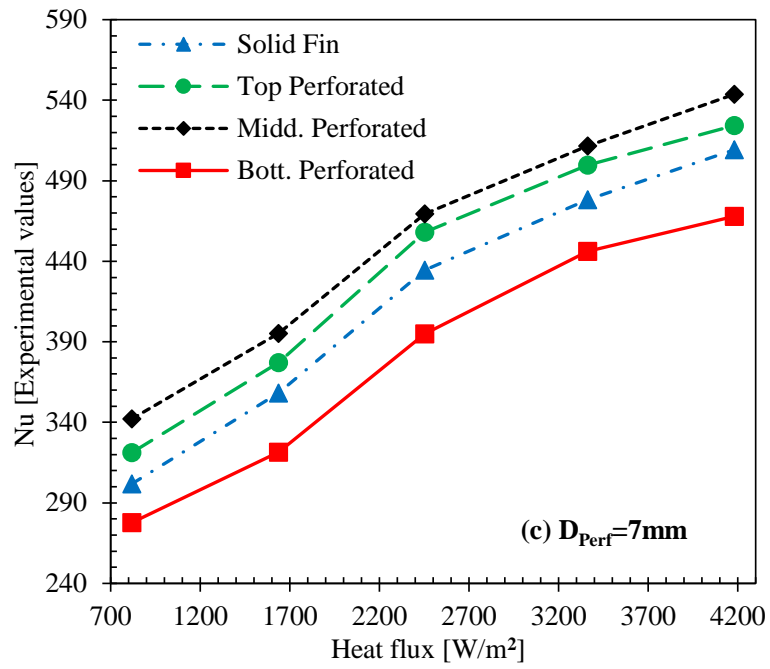

Figure 3 Nusselt number vs. heat flux at perforation diameters (Derf) of $3.0 \mathrm{~mm}(\mathrm{a}), 5.0 \mathrm{~mm}(\mathrm{~b}), 7.0 \mathrm{~mm}$ (c)

\subsubsection{Effect of the Perforations Position (Bottom, Middle, Top) on the Thermal Performance}

Comparing the effect of perforations position on the fin's thermal performance, the middle perforation position performs the best alongside the supplied heat flux compared with the top and bottom perforations positions. When the flux is $4181.8 \mathrm{~W} / \mathrm{m}^{2}$, the middlepositioned perforations give the best thermal performance improvement in terms of Nu number, as shown in Figure $3(\mathrm{a}-\mathrm{c})$. Accordingly, the greatest Nu numbers are $662.08,604.53$ and 543.72 at perforations diameters $3.0 \mathrm{~mm}, 5.0 \mathrm{~mm}$, and $7.0 \mathrm{~mm}$ respectively. This performance could be attributed to two main reasons. Firstly, the fin base of the middle perforations position may transfer a greater amount of heat from source to the entire fin by conduction [15]. This can be partly explained by the increased fin base temperature and the maximum temperature reduction between the fin base and tip, as shown in Figure 4. A larger temperature reduction across the fin means that more supplied heat can be conducted and distributed over the entire fin body. This thermal performance may lead to increase the mass of the bounced air over the fin surface, which tends to dissipate a greater amount of the conducted heat via convection heat transfer to the surrounding. Consequently, the main heat transfer methods (conduction and convection) may work cooperatively as a prime mover of the heat dissipation from the source to the surrounding. Secondly, the increased surface temperature could lead to enhance the furbulence of the bounced air inside the perforations. Subsequently, the thermal sublayers near the fin surface might be decreased resulting in greater heat dissipation and better thermal performance. This can be clearly noticed in Figures 3 and 4 where the Nu number increased with decreased Derf and increased surface temperature.

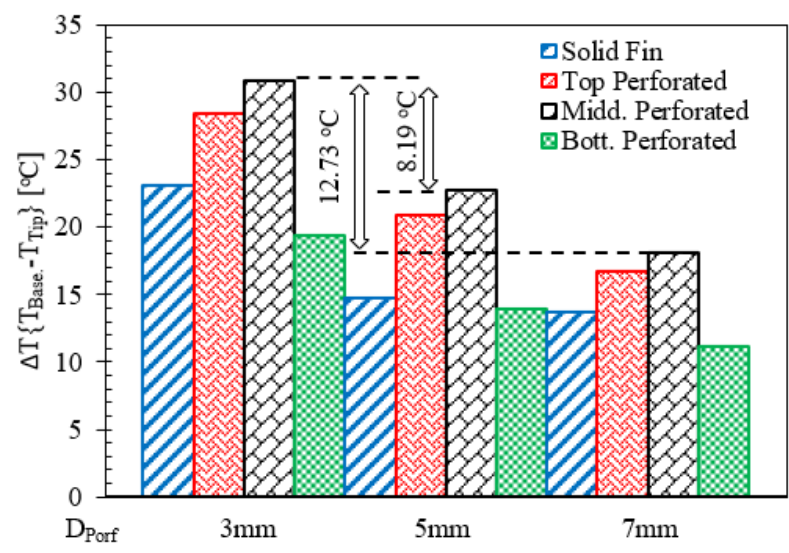

Figure 4 Temperature reduction across the tested fins at $4181.8 \mathrm{~W} / \mathrm{m}^{2}$

\subsubsection{Effects of Perforations Position (Top and Bottom) on the Thermal Performance}

Figures 3 (a-c) demonstrate that at the used diameters, the thermal performance slightly deteriorates when the three perforations rows are positioned at the top of the used fins. Compared with the middle-perforated fins, the results of Nu numbers decrease by $5.23 \%, 3.17 \%$ and $6.54 \%$ when Derf are 3.0 $\mathrm{mm}, 5.0 \mathrm{~mm}$ and $7.0 \mathrm{~mm}$ respectively. The first influential parameter that might affect the Nu number is the thermal resistance which strongly related to the perforations cut and generated area shown in Figures 2 and 5. The top-perforated fins could have a smaller thermal resistance at the first two-thirds of the fin body, which may tend to transfer more heat from the source to the fin. Nevertheless, it is well known that the temperature distribution for a conventional rectangular fin starts from high temperature near the heat source, and it decreases gradually to the lowest temperature at the fin tip due to mainly the effect of thermal resistance, and the heat dissipation to the surrounding as a second reason [15]. Consequently, the surface temperature could be decreased where the top perforations are located, as shown in Figure 4. The decreased temperature may tend to reduce the effectiveness of heat transfer by convection from the fin surface to the surrounding. Furthermore, a colder surface temperature means less bounced-air mass in the vicinity of the fin perforations thus a weaker turbulence flow may be created. This may result in inefficient convection heat transfer between the top perforated fin part and the surrounding. This may partly explain the decrement of Nu at all the supplied heat flux when the top-perforated fin is used compared with that of the middle-perforated fin, as shown in Figures 3 (a-c).

On the other side, the bottom-perforated fins perform the worst in term of the Nu numbers results. Compared with that of the middle-perforated fins, the Nu number was decreased by $14.15 \%, 11.73 \%$ and $23.18 \%$ at perforations diameters of $3.0 \mathrm{~mm} 5.0 \mathrm{~mm}$ 
and $7.0 \mathrm{~mm}$ respectively. The removed metal from the first third of fins body (near the heat source) may play an important role in increasing the thermal resistance in this crucial part of the fins. This could substantially increase the heat accumulation at the bottom of the fin caused by the reduction in the heat transfer by conduction from the heat source to the rest of the fin [13]. This may lead to two severe consequences on the fin's thermal performance. Firstly, the accumulated heat at the bottom of the fins means that the temperature is not evenly distributed throughout the fins body. Subsequently, the temperature can be exceedingly high before the perforations and low after them (at the top two thirds of the fin's body). As a result of that, not all the fin's body can effectively dissipate the heat to the surrounding. Secondly, although a greater body temperature means higher heat radiation, the thermal sublayers in the vicinity of the fin surface might be extremely thickened. This could strongly reduce the heat transfer from the fin's surface to the ambient by convection [18]. In addition, stronger thermal sublayers in the vicinity of perforations could weaken the effect of the turbulent flow in enhancing the convection heat transfer.

\subsubsection{Effect of Perforation Diameter (DPerf) on the Thermal Performance}

Figures $3(a-c)$ show the differences in the Nu number results against the changing in the Dperf of the tested fins. It can be noticed that the maximum mean values of the Nu number are achieved when the Dperf is 3.0 $\mathrm{mm}$, but the minimum values are matched at $7.0 \mathrm{~mm}$ Dperf. This is because of being that the removed circular metal from the fin body acts on generating additive surface area inside the hole of $3.0 \mathrm{~mm}$ diameter, which tends to enhance the heat transfer by convection. On the other side, when the Derf 7.0 $\mathrm{mm}$ is used, the removed metal does not generate an addition area, but it reduces the convective surface area of the adopted fins, as shown in Figure 5. This tends to reduce the values of the $\mathrm{Nu}$ number compared with that of the $3.0 \mathrm{~mm}$ and $5.0 \mathrm{~mm}$ perforated fins. Moreover, a smaller surface area may act to reduce the heat transfer by convection inside the holes resulting in a lesser mean value of the Nu numbers compared to the other perforated fins.

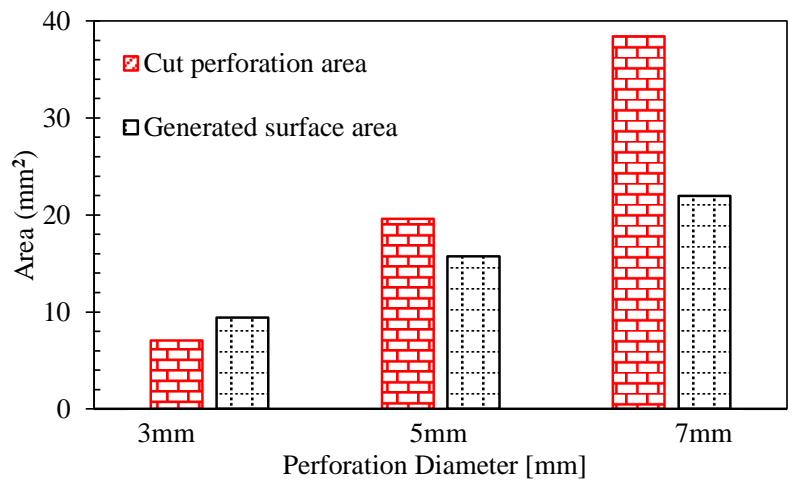

Figure 5 Generated surface area vs. perforation diameter (Dperf)

\subsection{Mean Surface Temperature}

Figures $6(a-c)$ shows the results of the mean surface temperature ( $\mathrm{T}_{\text {Mean }}$ ) that measured at a wide range of the used heat flux and various perforations parameters. It can be noticed that the $T_{\text {Mean }}$ values increase with the increased supplied heat flux at all the used fins. At $3.0 \mathrm{~mm}$ Derf, the maximum measured $T_{\text {Mean }}$ is $71.95{ }^{\circ} \mathrm{C}$ when the maximum heat flux 4.2 $\mathrm{kW} / \mathrm{m}^{2}$ is used, and the fins are middle-perforated, as shown in Figure (6-a). On the other side, at $7.0 \mathrm{~mm}$ Derf, the lowermost TMean $30.31{ }^{\circ} \mathrm{C}$ is noticed when fins are bottom-perforated, and the minimum heat flux $0.82 \mathrm{~kW} / \mathrm{m}^{2}$ is supplied. This thermal performance could be attributed to the increased supplied heat flux on the fin's base, which means more heat can be conducted over the entire fin's body rising the mean temperature value of the fins surface [15]. Moreover, the increased thermal resistance in the first third of the fins body could lead to accumulate the heat at this part when the fins are bottom-perforated. This could result in a weak heat transfer by conduction and unequal temperature distribution throughout the fin's body. This could partly explain the reduction of the $T_{\text {Mean }}$ when the solid fins are bottom-perforated. In addition, positioning the perforations near the heat source might increase the radiation heat transfer activity from the heat source to the perforations zone resulting in a more heat could be accumulated at this part of the fin [19]. Consequently, the induced turbulence of the bounced air may not be able to clear the bounded thermal sublayers at the fin surface due to increasing the thermal resistance. The $\mathrm{T}_{\text {Mean }}$ results shown in Figures $6(a-c)$ are highly correlated with Nu number results shown in Figures $3(a-c)$.

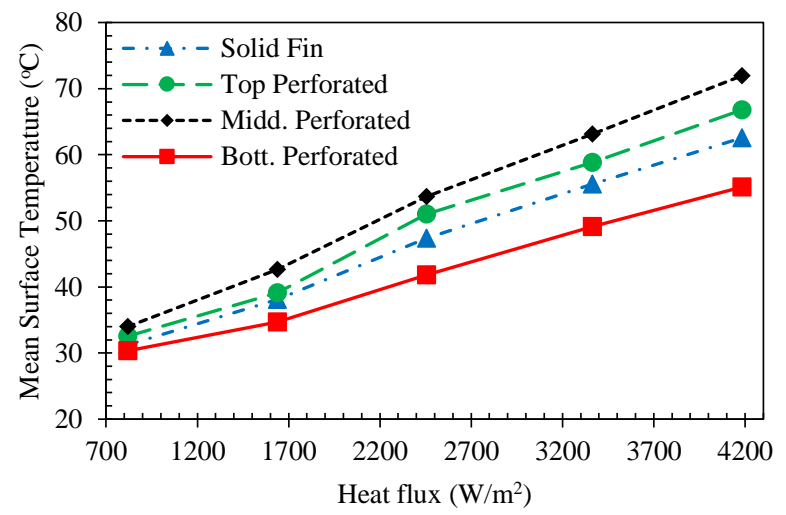

Figure (6-a) Mean surface temperature vs Heat flux at 3.0 $\mathrm{mm}$ perforation diameter (Dperf) 


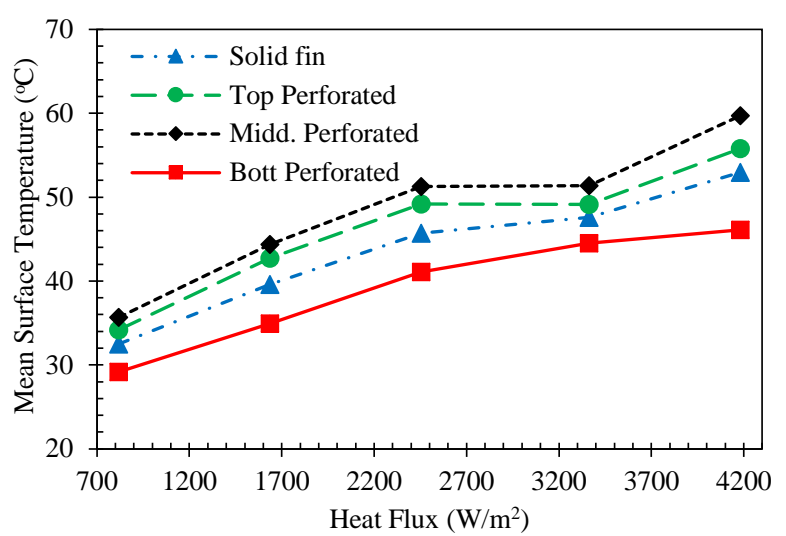

Figure (6-b) Mean surface temperature vs Heat flux at 5.0 $\mathrm{mm}$ perforation diameter (Derf)

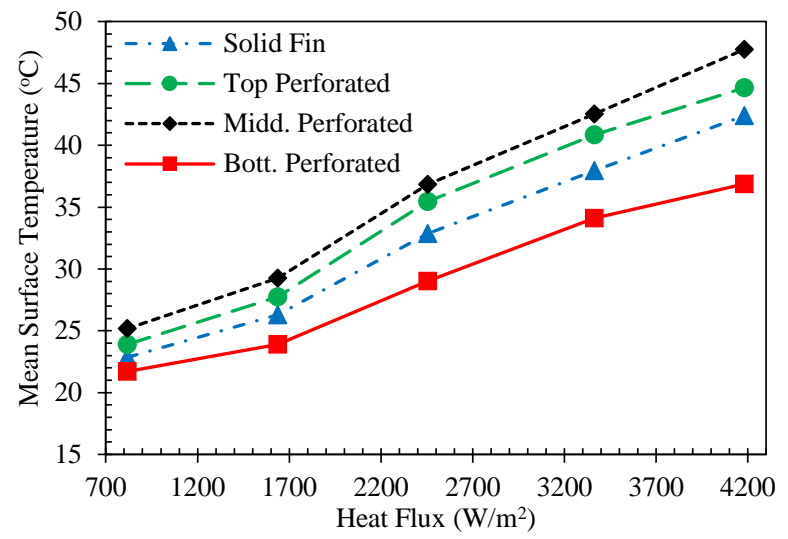

Figure (6-c) Mean surface temperature vs Heat flux at $7.0 \mathrm{~mm}$ perforation diameter (Derf)

As shown in Figures 6(a-c), it can be noticed that the position of the perforations plays an important role in results of the TMean value of the solid fin. Regardless the effect of the Derf, $T_{\text {Mean }}$ increases when the rows of perforations are used and positioned at the top and middle of the solid fins. When the perforation diameter is $3 \mathrm{~mm}$, the $\mathrm{T}_{\text {mean }}$ increases by $13.09 \%$ and $7.28 \%$ when the perforations are middle and top-positioned respectively compared to that of the solid fin, as shown in Figure (6-a). This might be due to the increased rate of heat transfer conducted throughout the fin body especially the solid part of the fin from the heat source to the entire fin body. This could associate with the increased mass flow rate of the bounced air, which is directly related to the fin surface temperature. Furthermore, the turbulent flow of the spring up air caused by perforations could strongly reduce the thickness of the thermal sublayers at the vicinity of the fin perforations [18]. This could significantly enhance the heat transfer by convection between the fin surface and surrounding. On the other hand, the Tmean consistently decreases when the perforations are positioned at the bottom of the fin at all the supplied heat flux as shown in Figures $6(a-c)$. This performance could be attributed to the accumulated heat caused by the increased thermal resistance at the first third of the fin body where a significant metal part of the fin body is cut. This could significantly lower the local fin surface temperature, which could deactivate the effect of the convection heat transfer at the top two thirds of the fins compared with the middle and topperforated fins. Moreover, the thermal sublayers at the first third of the fin could be much thicker due to the rise of the local surface temperature resulting in a poorer heat transfer to the surrounding.

\subsection{CONCLUSION}

The flat-plate fins have been vastly used due to their simple design and effective thermal performance. In this study, three rows of circular perforations are used aiming to increase the fins surface area which can enhances the heat transfer rate to the surrounding in natural convection conditions. The effect of the perforation's positions and their diameters on the fin thermal performance are also experimentally investigated. The causes behind the attained improvement in the thermal performance of the perforated fins are fundamentally explained.

The achieved results showed that the maximum improvement in the thermal performance occurs when the perforations are positioned at the middle of the fin regardless of the diameter. Compared with the solid fin, the maximum increments of the Nu number are $6.48 \%, 7.07 \%$ and $11.79 \%$ when the fins are middleperforated, and the used diameters are $3.0 \mathrm{~mm}, 5.0$ $\mathrm{mm}$, and $7.0 \mathrm{~mm}$ respectively. Moreover, the mean surface temperature increases by $13.09 \%, 11.24 \%$, $14.54 \%$ at the perforated diameters of $3.0 \mathrm{~mm}, 5.0 \mathrm{~mm}$ and $7.0 \mathrm{~mm}$ respectively.

It is also found that the perforation diameter of 3.0 $\mathrm{mm}$ shows the maximum Nu number and mean surface temperature compared to that of $5.0 \mathrm{~mm}$ and $7.0 \mathrm{~mm}$ regardless the perforations positions. This may also influence the mean surface temperature, which are at their maximum values when the perforations are the middle position.

\section{Symbols and Abbreviations}

\begin{tabular}{|l|l|}
\hline Symbol & Meaning \\
\hline AVR & Automatic voltage Regulator \\
\hline$R$ & Radius \\
\hline$q^{\prime \prime}$ & Heat flux \\
\hline $\mathrm{l}$ & Electric current \\
\hline $\mathrm{V}$ & Electric voltage \\
\hline Across & Area cross section of the heat source \\
\hline $\mathrm{Nu}$ & Nusslte number \\
\hline $\mathrm{h}$ & Heat flux \\
\hline Asurf. & Surface area of the fin \\
\hline Tmean & $\begin{array}{l}\text { Mean temperature over the fin surface } \\
\text { measured from multi points by } \\
\text { thermocouple }\end{array}$ \\
\hline To & $\begin{array}{l}\text { The environmental temperature of the } \\
\text { lab room }\end{array}$ \\
\hline Aperf. & The surface area of the cut perforation \\
\hline
\end{tabular}




\begin{tabular}{|l|l|}
\hline Symbol & Meaning \\
\hline $\begin{array}{l}\text { Asurf./soild } \\
\text { fin }\end{array}$ & $\begin{array}{l}\text { The surface area of the solid fin without } \\
\text { any perforations }\end{array}$ \\
\hline$T_{\text {film }}$ & The film temperature \\
\hline Derf & The perforation diameter \\
\hline Midd. & Middle \\
\hline Bott. & Bottom \\
\hline
\end{tabular}

\section{References}

[1] Huang, C.-H., Liu, Y.-C., and Ay, H. 2015. The Design of Optimum Perforation Diameters for Pin Fin Array for Heat Transfer Enhancement. International Journal of Heat and Mass Transfer. 84752-765.

[2] Jafari, D., and Wits, W. W. 2018. The Utilization of Selective Laser Melting Technology on Heat Transfer Devices for Thermal Energy Conversion Applications: A Review. Renewable and Sustainable Energy Reviews. 91420-442.

[3] Shaeri, M. R., and Yaghoubi, M. 2009. Numerical Analysis of Turbulent Convection Heat Transfer from an Array of Perforated Fins. International Journal of Heat and Fluid Flow. 302: 218-228.

[4] Shaeri, M. R., and Bonner, R. W. 2019. Analytical Heat Transfer Model for Laterally Perforated-finned Heat Sinks. International Journal of Heat and Mass Transfer. 1311164 1173.

[5] Ahmed, H. E., Salman, B. H., Kherbeet, A. S., and Ahmed, M. I. 2018. Optimization of Thermal Design of Heat Sinks: A Review. International Journal of Heat and Mass Transfer. $118129-153$.

[6] Kumar, S., Kumar, A., Darshan Kothiyal, A., and Singh Bisht, M. 2018. A Review of Flow and Heat Transfer Behaviour of Nanofluids in Micro Channel Heat Sinks. Thermal Science and Engineering Progress. 8477-493.

[7] Shaeri, M. R., Yaghoubi, M., and Jafarpur, K. 2009. Heat Transfer Analysis of Lateral Perforated Fin Heat Sinks. Applied Energy. 8610: 2019-2029.

[8] Calautit, J. K., Hughes, B. R., Chaudhry, H. N., and Ghani, S. A. 2013. CFD Analysis of a Heat Transfer Device Integrated Wind Tower System for Hot and Dry Climate. Applied Energy. 112576-591.
[9] Elshafei, E. A. M. 2010. Natural Convection Heat Transfer from a Heat Sink with Hollow/Perforated Circular Pin Fins. 2010 3rd International Conference on Thermal Issues in Emerging Technologies Theory and Applications. 185-193.

[10] Ibrahim, T. K. et al. 2018. Experimental Study on the Effect of Perforations Shapes on Vertical Heated Fins Performance Under Forced Convection Heat Transfer. International Journal of Heat and Mass Transfer. 118832-846.

[11] Huang, C.-H., and Chen, M.-H. 2019. An Estimation of the Optimum Shape and Perforation Diameters for Pin Fin Arrays. International Journal of Heat and Mass Transfer. 13172-84.

[12] Al-Damook, A., Kapur, N., Summers, J. L., and Thompson, H. M. 2015. An Experimental and Computational Investigation of Thermal Air Flows through Perforated Pin Heat Sinks. Applied Thermal Engineering. 89365-376.

[13] Awasarmol, U. V., and Pise, A. T. 2015. An Experimental Investigation of Natural Convection Heat Transfer Enhancement from Perforated Rectangular Fins Array at Different Inclinations. Experimental Thermal and Fluid Science. 68145-154.

[14] Al-Doori, W. 2011. Enhancement of Natural Convection Heat Transfer from the Rectangular Fins by Circular Perforations. International Journal of Automotive and Mechanical Engineering (IJAME). 4: 428-436.

[15] Cengel, Y. A. 2002. Heat Transfer. Second Edition Ed. Mcgraw-Hill.

[16] XU, H. J., Xing, Z. B., Wang, F. Q., and Cheng, Z. M. 2019. Review on Heat Conduction, Heat Convection, Thermal Radiation and Phase Change Heat Transfer of Nanofluids in Porous Media: Fundamentals and Applications. Chemical Engineering Science. 195462-483.

[17] Shaeri, M. R., and Jen, T.-C. 2012. The Effects of Perforation Sizes on Laminar Heat Transfer Characteristics of an Array of Perforated Fins. Energy Conversion and Management. 64328-334.

[18] Bernardes, M. A. D. S. 2011 . Developments in Heat Transfer. Croatia: InTech.

[19] Mert Cuce, P., and Cuce, E. 2013. Optimization of Configurations to Enhance Heat Transfer from a Longitudinal Fin Exposed to Natural Convection and Radiation. International Journal of Low-Carbon Technologies. 94: 305-310. 